\section{Prevalence of hepatitis C viral infection among injecting drug users in a Saudi Arabian hospital: A point cross sectional survey}

Osama A. Alibrahim, ${ }^{1}$ Yusuf A. Misau, ${ }^{2}$ Alkali Mohammed, ${ }^{3}$

Mohammad Bashir Faruk, ${ }^{3}$ Izzeldin SS, ${ }^{1}$

${ }^{1}$ Al-Amal Hospital, Jeddah, Kingdom of Saudi Arabia; ${ }^{2}$ Department of Community Medicine, Abubakar Tafawa Balewa University, Bauchi; ${ }^{3}$ Department of Internal Medicine, Abubakar Tafawa Balewa University Teaching, Bauchi Nigeria

\begin{abstract}
Hepatitis C Virus is an important cause of preventable morbidity and mortality among Injecting Drug Users worldwide. The aim of this study is to determine the prevalence and correlations of $\mathrm{HCV}$ infection among IDUs in Saudi Arabia. A point cross-sectional survey was conducted between May 2012 and Nov 2012 to determine hepatitis $\mathrm{C}$ viral antibodies serological status using venous blood among IDUs $(\mathrm{N}=300)$ accessing care at Al-Amal Hospital in the Kingdom of Saudi Arabia, as well as to determine clinical correlates of hepatitis $\mathrm{C}$ infection among the Injecting Drug Users. There was an overall HCV prevalence of $42.7 \%$ among IDUs studied. Low level primary education, single marital status, being unemployed and commencing Injecting Drugs beyond the age of 15 years have higher specific prevalence of $\mathrm{HCV}$ among IDUs population. There was statistically significant association between clinical assessments of the participants who were abusing drugs generally, dependent on drugs, specifically abusing cocaine, amphetamines, opioids, cannabinoids and alcohol with HCV antibodies seropositivity. There was no statistical significant relationship between drug induced sleep/sexual disorder and psychosis/delusion with $\mathrm{HCV}$ seropositivity. This study demonstrated a relatively high prevalence of $\mathrm{HCV}$ among IDUs in KSA. Targeted public health preventive strategies are necessary to halt the spread of HCV among IDUs in KSA. The resultant benefits of these will include reduction in morbidity and mortality as well as improved socioeconomic wellbeing of the IDU's population.
\end{abstract}

\section{Introduction}

There has been an exponential increase of Hepatitis C Virus (HCV) infection among Injecting Drug Users (IDUs) globally in the past one decade even when there are evidence of decline of HIV prevalence among the IDUs, HCV remains alarmingly high despite all efforts. ${ }^{1,2}$ Couple with high economic burden of treating $\mathrm{HCV}$ as well as care for the rehabilitation of IDUs, interests among researchers has remain high towards understanding the matrix of HCV among IDUs among others. ${ }^{3}$ The high morbidity and mortality due to HCV among IDUs could easily be preventable. The World Health Organization (WHO) has still reported inadequacy of understanding of treatment, care and prevention of $\mathrm{HCV}$ infection among IDUs.

$\mathrm{HCV}$ is easily transmissible by sharing of non-sterile syringe among IDUs, who already have documented high population prevalence of $43-67 \%$ among life-time users. The infection has been at an epidemic proportion since the 1960s until 1990s thus preceding and exceeding the epidemics of Human Immune deficiency Virus (HIV) globally. In the United States, The City of New York alone, 90\% of IDUs had HCV infection in the 1990s. ${ }^{4}$ The global prevalence of $\mathrm{HCV}$ has recently been estimated at $1.7 \%$ or 115 million cases which yet exceed the global burden of HIV/AIDS. ${ }^{5}$

There are few studies targeting IDUs in the Middle East in the recent past. ${ }^{6}$ However no previous study has assessed HCV among IDUs in the Kingdom of Saudi Arabia (KSA) and the prevalence of IDUs among people aged 15-64 years in KSA has also not been well established. ${ }^{7}$ This has constituted a huge gap in the harm reduction programs for IDUs in KSA. A combined regional estimate of $5-60 \% \mathrm{HCV}$ prevalence among IDUs has been reported from a review of published studies in the Middle East. ${ }^{8}$ Since significant HCV prevalence reduction has been reported among IDUs subjected to intervention programs like needle and syringe exchange program (SEP) and medication assisted treatment (MAT). ${ }^{4}$ This study aims at determining the prevalence of HCV infection among IDUs population in KSA and to identify significant correlates associated with HCV infection among IDUs population in KSA.

\section{Materials and Methods}

We conducted a point cross sectional survey between May 2012 through Nov 2012 among IDUs accessing care at AlAmal Hospital Jeddah in the KSA. The Al-
Correspondence: Yusuf Abdu Misau, Department of Community Medicine, College of Medical Sciences, Abubakar Tafawa Balewa University Bauchi, PO Box 2231 Bauchi, Nigeria.

Tel.: +234.8035.796.880.

E-mail: yusufmisau@yahoo.com

Key words: hepatitis C; drug users; hospital; Saudi Arabia.

Contributions: the authors contributed equally.

Conflict of interest: the authors declare no potential conflict of interest.

Funding: none

Received for publication: 15 June 2017

Accepted for publication: 29 September 2017.

This work is licensed under a Creative Commons Attribution NonCommercial 4.0 License (CC BY-NC 4.0).

(C) Copyright O.A. Alibrahim et al., 2018

Licensee PAGEPress, Italy

Journal of Public Health in Africa 2018; 9:726 doi:10.4081/jphia.2018.726

Amal Hospital Jeddah is a referral center for treatment of drug addiction in KSA. Participants who were either on follow up, accessing care on first presentation or referred from another center, were recruited during contacts in the specialist's clinic. IDUs who were eligible for the survey were defined as any person aged between 18 to 49 years who has injected drugs recreationally at least once in the past 12 months. To produce a national-level estimate of $\mathrm{HCV}$ prevalence among IDUs, a sample size was calculated, with an assumed HCV prevalence of 5\%, a design effect of 1.5-2.0 and a set precision level of 0.05 , a total sample to be achieved was 300. No incentive was given for participation and subjects who declined informed consent were assured of continuous care in the center irrespective of their decision not to participate. After obtaining consent, data were collected using interviewer administered study tool by Doctors and Nurses who were trained to administer the tool. A brief rejecter questionnaire was developed for any IDU who declined participation to allow for an estimation of the attrition rate.

Data were collected on socio-demographic characteristics, drug use, and high risk sexual behavior in the past 6 months. Drug use-related questions included the age at which the patient started use and the route of drug administration. Injection drug use was defined as any injection of drugs during 
the patient's lifetime (Have you ever used drugs by injection?).

A pretest counseling session conducted by certified $\mathrm{HCV}$ counselors at the time of phlebotomy were performed for every participant after questionnaire administration. Blood samples were then collected for HCV antibodies detection using ELISA and a confirmatory test. Participants were asked to return two weeks after the baseline visit, for their HCV antibody test results and posttest counseling.

All participants were given information on HCV infection, including details on the natural history of $\mathrm{HCV}$ infection and the high infectivity rate of $\mathrm{HCV}$, participants were counseled to avoid sharing needles, syringes, and other injection equipment to reduce the risk of $\mathrm{HCV}$ transmission and were counseled to use needle exchange programs. However, participants found to be positive for $\mathrm{HCV}$ antibody were referred to a counselor with expertise in HCV infection for more elaborate discussion on how to lessen the risk of progression to liver disease including the need to cease or reduce alcohol ingestion. Safe injection practices were encouraged and the HCV-positive participants were referred to see a hepatologist physician for treatment.

Data was analyzed using Statistical Package for the Social Sciences (SPSS). First uni-variate and then cross tabulation was used to explain possible relationship between the variables. To determine the significance of association we applied chisquare test for categorical variables. The significance level (P-value) was set as $<0.05$ at $95 \%$ CI.

\section{Results}

A total of 300 male IDUs consented and participated in the survey among which majority were single $170(56.7 \%)$. Of the single participants, $78(45.9 \%)$ were $\mathrm{HCV}$ positive. However, most of the participants were employed $178(59.3 \%)$ although there was higher prevalence of HCV with positive results among $54(44.3 \%)$ of the 122 (40.7\%) unemployed IDUs. Most of the participants were educated to the level of secondary school only 133 (44.3\%), however those having only the primary school level of education have higher prevalence of HCV with prevalence of 38(57.6\%). IDUs who initiated injection at age greater than 15 years were more among the surveyed participants, $266(88.7 \%)$ and also had higher prevalence of HCV infection $126(47.4 \%)$ compared with those who initiate injection below the age of 15 years (Table 1). About 49 (16.3\%) of the respon- dents has legal problems as at time of the participation in this survey. $26(\%)$ have history of family abuse. And $66(22.0 \%)$ of the IDUs uses alcohol at least once in a day. Overall prevalence of $\mathrm{HCV}$ antibody among IDUs surveyed was $42.7 \%$.

$\mathrm{HCV}$ antibody status was tested against clinical status of respondents using chisquare test of association. Highly significant association was found between $\mathrm{HCV}$ antibodies status with clinical statuses of drug abuses and drug dependence. Also on test of association with specific drugs, opioids, cannabis, cocaine, amphetamines and alcohol. There was no significant association between clinical status of drug induced sleep disorder, drug induced sexual disorder, delusion, drug induced psychosis and $\mathrm{HCV}$ antibodies status.

\section{Discussion}

This study attempted to provide scientific evidence of burden of $\mathrm{HCV}$ among increasing population of IDUs in KSA and to also determine association between $\mathrm{HCV}$ and clinical status of participants (Table 2). The study shows relatively lower prevalence of HCV among IDUs in KSA (42.7\%) as compared with the global prevalence rates of $55-95 \%$ as reported elsewhere in the literature. ${ }^{9}$ Yet, this study shows KSA has higher prevalence of HCV among IDUs compared with other middle east countries such as Iran with $34 \% \mathrm{HCV}$ prevalence among IDUs, ${ }^{6}$ and even among some North American countries such as Brazil. ${ }^{10}$ Participants with low level primary education, history of family abuse, and unemployed have higher prevalence of HCV antibodies. Only male were enrolled in this study as there were no female IDUs appearing in the study center throughout the study duration. Previous studies have though documented gender variations in HCV among IDUs. ${ }^{11,12}$ Analysis of baseline characteristics in Table 2 above shows HCV prevalence is considerably high across all characteristics. Whereas most previous studies

Table 1. Baseline characteristics and prevalence of hepatitis $C$ virus infection among injecting drug users in Jeddah, Saudi Arabia.

\begin{tabular}{lccc} 
Characteristics & Total & N. & $\%$ \\
Gender(Male) & 300 & 128 & 42.7 \\
Married & 130 & 50 & 38.5 \\
\hline Single & 170 & 78 & 45.9 \\
Employed & 178 & 74 & 41.6 \\
\hline Unemployed & 122 & 54 & 44.3 \\
Primary Education & 66 & 38 & 57.6 \\
\hline Secondary Education & 133 & 40 & 30.1 \\
University Education & 22 & 9 & 40.9 \\
\hline Age at start of injection $<15 y r s$ & 34 & 2 & 5.9 \\
Age at start of injection $>15 y r s$ & 266 & 126 & 47.4 \\
\hline Family History of Abuse & 26 & 13 & 50.0 \\
Legal Problem & 49 & 73 & 67.0 \\
\hline Alcohol ingestion & 10 & 30 & 33.3 \\
\hline
\end{tabular}

Table 2. Participant's clinical status and hepatitis $\mathrm{C}$ virus status among injecting drug users in Jeddah, Saudi Arabia.

\begin{tabular}{lcccc} 
Status & $\mathbf{N}$ & \% HCV $(+)$ & \% HCV (-) & P-value \\
Drug Abuse & 40 & 35.0 & 65.0 & 0.000 \\
Drug Dependence & 260 & 43.8 & 56.2 & 0.001 \\
\hline Opioids Abuse & 133 & 93.2 & 6.8 & 0.000 \\
Cocaine Abuse & 3 & 66.7 & 33.3 & 0.000 \\
\hline Cannabinoids Abuse & 137 & 24.1 & 75.1 & 0.000 \\
Amphetamines Abuse & 154 & 7.8 & 92.2 & 0.001 \\
\hline Alcohol Abuse & 66 & 34.8 & 65.2 & 0.003 \\
Drug Induced Sleep Disorder & 65 & 50.8 & 49.2 & 0.198 \\
\hline Drug Induced Sexual Disorder & 13 & 38.5 & 61.5 & 0.657 \\
Delusion & 68 & 63.3 & 36.7 & 0.008 \\
\hline Drug induced Psychosis & 33 & 70.0 & 30.0 & 0.136 \\
\hline
\end{tabular}


focuses on HCV prevalence and associated risk factors among IDUs, this study looked at the both prevalence and relationship between clinical status of IDUs and HCV seropositivity. This has added more understanding as to the dimensionality of $\mathrm{HCV}$ antibodies status and clinical status of IDUs. Previous studies were mostly unable to establish significant association between $\mathrm{HCV}$ and known injection risk behaviors because nearly all IDUs studied tends to be HCV positive. ${ }^{13}$ Consequently, we found that there is statistically significant association between clinical assessments of the participants who abuse drugs, dependent on drugs, abusing cocaine, abusing amphetamines, abusing opioids, cannabinoids and alcohol abuse with HCV antibodies seropositivity. There was no statistical significant relationship between drug induced sleep/sexual disorder and psychosis/delusion with HCV seropositivity.

Needle sharing or use of contaminated needles is a very efficient way of spreading $\mathrm{HCV} / \mathrm{HIV}$ which keeps the wave of both $\mathrm{HCV}$ and HIV epidemic on the increase among Injecting Drug Users (IDUs) who share needles. In some regions of the developing world IDUs are the primary drivers of HIV infection accounting for over $70 \%$ of new infections in these regions, yet less than $20 \%$ of IDUs are accessing Hepatitis and HIV care services globally. ${ }^{8}$ Although the ...advances made in treatment of chronic hepatitis $\mathrm{C}$ virus (HCV) infection in recent years have provided considerable optimism for people living with $\mathrm{HCV}$ infection, as well as for their clinicians. Despite these advances, the numbers of people developing complications of $\mathrm{HCV}$-related advanced liver disease continue to increase. ${ }^{14}$ The treatment for HCV is usually very expensive, complicated, and may not always be successful. Currently, the best treatment available consists of pegylated interferon alpha plus ribavarin, which produces a sustained virologic response in 30 to $80 \%$ of treated patients. Response rates vary depending on the HCV genotype of the patient, with lower response rates of 30 to $40 \%$ seen in patients infected with genotype $1 .^{15}$ Treatment with pegylated alpha $2 \mathrm{a}$ interferon cost \$270 US per week and needs to be taken weekly for six months to one year. In Saudi Arabia, this cost of treatment will ranges from 1000-1200 SAR per week, with $44 \%$ of the studied IDUs as unemployed, cost of care can be a significant factor in driving the infected IDUs to chronic disease state.

In an attempt to reduce the burden of damages from illegal injection practices, public health strategies aimed at harm reductions among IDUs have been used in many countries with varying degrees of outcomes. In Saudi Arabia to the best of our knowledge there are no instituted government funded harm reduction projects targeting IDUs population.

The harm reduction programs, treatment centers and substituted prescription have been used to reduce both the health and social problems associated with injection drug practices

\section{Conclusions}

Our study shows the prevalence of $\mathrm{HCV}$ among IDUs in Saudi Arabia is relatively high as in most other parts of the world. IDUs in Saudi Arabia are mostly unemployed with low level of education with associated clinical sequela. Urgent public health strategies are needed to provide harm reduction measures among IDUs in Saudi Arabia.

\section{References}

1. Zibbell JE, Iqbal K, Patel RC, et al. Increases in Hepatitis C Virus Infection Related to Injection Drug Use Among Persons Aged $\leq 30$ Years - Kentucky, Tennessee, Virginia, and West Virginia, 2006-2012. MMWR Morb Mortal Wkly Rep 2015;64:453-8.

2. Wiessing L, Likatavicius G, Hedrich D, et al. Trends in HIV and hepatitis C virus infections among injecting drug users in Europe, 2005 to 2010. Euro Surveill 2011;16:1-5.

3. Fisher DG, Kuhrt-Hunstiger TI, Orr SM, Davis DC. Knowledge regarding Hepatitis C among injecting drug users. Drugs Educ Prevent Policy 1999.

4. Jordan AE, Des Jarlais DC, Arasteh K, et al. Incidence and prevalence of hepatitis c virus infection among persons who inject drugs in New York City: 2006-2013. Drug Alcohol Depend 2015;152:194-200.

5. Connor PO, Judson G, Loan RA, et al. Prevalence of hepatitis $\mathrm{C}$ among injecting drug users attending drug clinics. New Zeal Med J 2016;129:44-8.

6. Amin-Esmaeili M, Rahimi-Movaghar
A, Razaghi EM, et al. Factors correlated with hepatitis $\mathrm{C}$ and $\mathrm{B}$ virus infections among injecting drug users in Tehran, IR Iran. Hepatitis Monthly 2012;12:2331.

7. Mathers BM, Degenhardt L, Phillips B, et al. Global epidemiology of injecting drug use and HIV among people who inject drugs: a systematic review. The Lancet 2008;6736:1-13.

8. Aceijas C, Rhodes T. Global estimates of prevalence of $\mathrm{HCV}$ infection among injecting drug users. (Hepatitis $\mathrm{C}$ prevention and care for injecting drug users). Int J Drug Policy 2007;22:252-8.

9. Garfein RS, Vlahov D, Galai N, et al. Viral infections in short-term injection drug users: The prevalence of the hepatitis $\mathrm{C}$, hepatitis $\mathrm{B}$, human immunodeficiency, and human T-lymphotropic viruses. Am J Public Health 1996;86: 655-61.

10. Silva MBS, Andrade TM, Silva LK, et al. Prevalence and genotypes of hepatitis $\mathrm{C}$ virus among injecting drug users from Salvador-BA, Brazil. Memorias Do Instituto Oswaldo Cruz 2010;105:299-303.

11. Gyarmathy VA, Neaigus A, Mitchell MM, Ujhelyi E. The association of syringe type and syringe cleaning with $\mathrm{HCV}$ infection among IDUs in Budapest, Hungary. Drug Alcohol Depend 2009;100:240-7.

12. Li D, Zheng X, Zhang G. (1994). [Prevalence of HIV and HCV among injecting drug users (IDUs) in Yunnan, China]. Zhonghua Liu Xing Bing Xue Za Zhi 1994;15:74-5. [Article in Chinese]

13. Thorpe LE, Ouellet LJ, Hershow R, et al. Risk of hepatitis $\mathrm{C}$ virus infection among young adult injection drug users who share injection equipment. Am J Epidemiol 2002;155:155:645-53.

14. Grebely J, Matthews GV, Hellard M, et al. Adherence to treatment for recently acquired hepatitis $\mathrm{C}$ virus (HCV) infection among injecting drug users. J Hepatol 2011;5:76-85.

15. White EF, Garfein RS, Brouwer KC, et al. Prevalence of hepatitis $\mathrm{C}$ virus and HIV infection among injection drug users in two Mexican cities bordering the U.S. Salud Publica de Mexico 2007;49:165-72.

16. Ramirez-Jonville A. Drug addiction: harm reduction policies in France and Spain. Presse Med 2006;35:1151-61. 